\title{
Gallbladder Carcinoma and Its Mimics
}

\author{
Praneeta Jaswant Singh ${ }^{1}$ and Sheetal G. Gole ${ }^{2 *}$ \\ ${ }^{1}$ Department of Pathology, K.D. medical College Hospital and Research Center, Akbarpur, Mathura, Uttar Pradesh, India \\ ${ }^{2}$ Department of Pathology, World College of Medical Science \& Research \& Hospital, Gurawar, Jhajjar, Haryana, India
}

\section{ABSTRACT}

Background: Symptomatic gallstone disease is most common indication for routine cholecystectomy. Gallstones cause various histological changes in gallbladder ranging from metaplasia to dysplasia and gallbladder carcinoma.

Aims: Study was conducted to evaluate histopathological lesions in gallbladder diseases, correlate clinical and histopathological diagnoses in cholecystectomies and to know prevalence of incidental gallbladder carcinoma in our region.

Method: All cholecystectomy specimens received in histopathology laboratory during study period of one year were included. Detailed gross and microscopic examination was done in each case. Slides were stained by Hematoxylin and Eosin stain.

Results: Total 290 cholecystectomy specimens were studied over a period of one year. Clinically suspicion of gallbladder carcinoma was raised in five cases due to preoperative and intraoperative findings of thickened gallbladder wall with adherence to surrounding structures and presence of gallstones. On microscopy, three cases of these were reported as xanthogranulomatous cholecystitis, one as nonspecific chronic cholecystitis and one was rare case of eumycetoma of gallbladder. On histopathological examination suspicion of gallbladder carcinoma was raised in three cases of dysplasia and final diagnosis was biliary intraepithelial neoplasia-3 in two cases and biliary intraepithelial neoplasia-1 in one case. Histopathologically two cases $(0.69 \%)$ were reported as gallbladder carcinoma and clinically there was no suspicion of gallbladder carcinoma in both cases. However in one case suspicion of gallbladder carcinoma was raised intraoperatively while one case was of incidental gallbladder carcinoma $(0.34 \%)$.

Conclusion: Gallstones disease can mimic gallbladder carcinoma clinically while incidental gallbladder carcinoma can occur in grossly normal looking gallbladder.

Keywords: Incidental Gallbladder Carcinoma; Eumycetoma; Biliary Intraepithelial Neoplasia; Dysplasia; Gallstone Disease; India

\section{Introduction}

Cholecystectomy specimens are routinely received in any histopathology laboratory. Most common indication for routine cholecystectomy is symptomatic gallstone disease. Prevalence of gallstones varies according to the age, sex and geographic areas. Overall prevalence of gallstones disease is higher in Indian subcontinent, especially in North India ${ }^{[1]}$. Also prevalence of gallbladder carcinoma (GBC), a rare disease, is reported to be highest in North India ${ }^{[2]}$. Gallstones are known to cause various histological changes in gallbladder ranging from metaplasia to dysplasia and even carcinoma of gallbladder. Up to $90 \% \mathrm{GBC}$ cases are found to be associated with gallstones ${ }^{[3-4]}$.

When GBC present as obvious gross abnormalities it can be detected on preoperative abdominal ultrasonography (USG). Sometimes preoperative diagnosis of GBC is difficult as symptoms and signs of patients mimic acute or chronic cholecystitis ${ }^{[5]}$. Long standing inflammatory conditions of gallbladder causes thickening of its wall which can mimic GBC on preoperative or intra operative examination. Sometimes early GBC does not present with any gross abnormalities and are diagnosed as incidental GBC on routine histopathological examination ${ }^{[6]}$. Review of literature shows incidence of incidental GBC in western countries varying from $0.3 \%$ to $2.85 \%$ while in Asian countries it varies from $0.62 \%$ to $5.9 \%{ }^{[4,7]}$.

The Royal College of Pathologists recommended routine histological examination in cholecystectomy specimens, as significant pathology may be present with normal gross morphology ${ }^{[8]}$. However recently this practice of routine examination of all cholecystectomy specimens is being challenged and studies have suggested selective submission of gallbladder specimens, showing gross abnormalities, for histological examination ${ }^{[9-11]}$. But whether this selective approach is justified in regions with high prevalence of gallstone disease and GBC is yet to be established.

Present study was conducted to correlate clinical and histopathological diagnoses in cholecystectomy specimens and to know prevalence of incidental GBC in our region. 


\section{Material and Methods}

This was a prospective cohort study conducted over a period of one year from January 2016 to December 2016 in the department of pathology, tertiary care hospital in North India. All cholecystectomy specimens received in our histopathology laboratory during the study period were included. Mostly we received already cut open specimens of gallbladder as surgeons perform gross examination to look for the presence gross abnormalities before submitting it for histopathological examination. In histopathological laboratory detailed gross examination was performed and size of gallbladder, external surface appearance along with presence of any lymph nodes was noted. Cut surface was examined to note appearance of mucosa, presence of any suspicious lesion, thickness of wall and presence of gallstones. Standard three sections were submitted each representing fundus, body and neck of gallbladder. Additional sections were submitted from suspicious areas. All sections were stained by Hematoxylin and Eosin (H\&E) stain. Periodic Acid Schiff (PAS) stain was applied if indicated. In cases of dysplasia, whole gallbladder was submitted for histopathological examination.

\section{Results}

Age and Sex: Total 290 cholecystectomy specimens were studied over a period of one year. Age of the patients ranged from 9 years to 76 years with mean age of 42.31. Maximum number of patients was in the age group of $31-40$ years $(24.82 \%)$. [Table no.1] Number of male patients was $66(22.76 \%)$ and that of female patients was $224(77.24 \%)$ with male to female ratio of 33:112.

Gross Examination: On gross examination, gallstones were found in 216 cases $(74.48 \%)$ while it was absent in 74 cases $(25.51 \%)$ [Table no. 2].

Out of total 290 cases, wall thickness was normal $(</=$ $0.3 \mathrm{~cm})$ in $197(67.93 \%)$ cases and it was increased $(>0.3)$ $\mathrm{cm}$ in 93 (32.06\%) cases. Mucosa was normal in 155 $(53.45 \%)$, atrophic in $119(41.03 \%)$, ulcerated in five cases $(1.72 \%)$, strawberry like in five $(1.72 \%)$, hyperplastic in three $(1.03 \%)$, slightly nodular in one $(0.34 \%)$ and black/ necrotic fragile in two cases $(0.69 \%)$

Gallbladder Lesions on Histopathological Examination: Chronic non specific cholecystitis was the most common diagnosis in 241 cases (83.14\%). [Table no. 3]

On microscopic examination following epithelial changes were noted: gastric antral metaplasia in 12 cases (4.13\%), intestinal metaplasia in 14 cases (4.82\%), hyperplasia in 16 cases $(5.51 \%)$ and dysplasia in three (1.03\%).
In three cases of dysplasia, gross examination showed increased wall thickness $(>3 \mathrm{~cm})$, atrophic to normal mucosa and presence of gallstones. On microscopy, all three cases were of non invasive dysplasia and were reported as Biliary intraepithelial neoplasia (BiIN) with classification into three grades as BiIN-1, BiIN-2 and BiIN-3 based on findings reported by Zen Y et al.[12]. Out of three cases of dysplasia, histopathological diagnosis was nonspecific chronic calculous cholecystitis with BiIN-3 in two cases and with BiIN-1 in one case. [Figure 1]

Out of six cases of adenomyomatosis, one case was each of focal and segmental adenomyomatosis and remaining four were of diffuse adenomyomatosis. Gross examination in all six cases showed increased wall thickness $(>0.3 \mathrm{~cm})$ with atrophic to normal mucosa. Gallstones were seen in three cases while it was absent in remaining three cases.

Clinically Suspected Cases of GBC: Clinical suspicion of $\mathrm{GBC}$ was raised in five cases based on preoperative USG findings of thickened gallbladder wall and presence of gallstones. Intraoperatively gallbladder was found to be thickened with adherence to surrounding structures in all five cases.. Grossly, gallbladder wall was thickened $(0.8-1 \mathrm{~cm})$ in all five cases, mucosa was atrophic in four cases and normal to atrophic in one case, and gallstones were present in all five cases. Lymph node was identified in four of these cases. On histopathology, three cases were reported as xanthogranulomatous cholecystitis with reactive lymphadenitis, one as nonspecific chronic cholecystitis with reactive lymphadenitis and one as chronic cholecystitis with eumycetoma.

In case of eumycetoma of gallbladder, a 55-year-old woman was admitted with complaints of pain in abdomen along with increased frequency of urine. Her general examination was within normal limit. Local examination revealed tenderness in right hypochondriac region and in lower abdomen. Random blood sugar was $185.5 \mathrm{mg} / \mathrm{dl}$. She was agricultural worker by occupation. Her laboratory work up was within normal limit except for raised TLC with neutrophilia. USG abdomen showed thickened gallbladder with multiple stones and cystic masses arising from anterior and posterior uterine wall. USG report was cholelithiasis and uterine fibroid with cystic degeneration. Intraoperatively suspicion of GBC was raised due to dense adhesions between contracted gallbladder and parities, small bowel and liver and presence of cholecysto-duodenal fistula.

In histopathology laboratory already cut open gallbladder specimen was received. Mucosa was normal to atrophic with blackened areas and wall thickness was $0.8-1 \mathrm{~cm}$. Microscopic examination revealed foci of brown to black 
colonies of branching, septate fungal hyphae embedded in a matrix [Figure 2]. PAS stain was positive for fungal hyphae while Gram stain was negative.

Cases of GBC on Histopathology : Two cases of GBC were diagnosed on histopathology in adult females with mean age of 40 years. Preoperatively there was no suspicion of malignancy in both cases. In one of the cases, clinical diagnosis was cholecystitis in 35 years old female. We received intact gallbladder specimen which on cut surface showed one small nodule of $0.8 \mathrm{~cm}$ in diameter at fundus while rest of the mucosa was normal and gallstone was absent. One lymph node was identified on external surface. Histopathological diagnosis was adenocarcinoma (NOS) with metastasis to regional lymph node (T1bN1) [Figure 3].

In another case, 45-year-old female presented as a case of symptomatic gallstone disease. Intraoperatively suspicion of GBC was raised with differential diagnosis of acute gangrenous cholecystitis due to adherence of gallbladder to omentum and liver and presence of necrotic black material in lumen. We received already cut open gallbladder with pigmented stone. Cut surface showed atrophic mucosa, black fragile tissue and thickened wall $(>0.3 \mathrm{~cm})$. Histopathological diagnosis was papillary adenocarcinoma (T1b).

Table 1: Age wise distribution of cases.

\begin{tabular}{|c|c|}
\hline Age group & Total number (\%) \\
\hline $0-10$ & $03(1.03)$ \\
\hline $11-20$ & $08(2.75)$ \\
\hline $21-30$ & $71(24.48)$ \\
\hline $31-40$ & $72(24.82)$ \\
\hline $41-50$ & $50(17.24)$ \\
\hline $51-60$ & $48(16.55)$ \\
\hline $61-70$ & $33(11.38)$ \\
\hline$>70$ & $05(1.72)$ \\
\hline
\end{tabular}

Table 2: Distribution of cases according to presence or absence of gallstones.

\begin{tabular}{|c|c|c|c|c|c|c|c|c|}
\hline \multirow[t]{3}{*}{ Gallstones } & \multicolumn{4}{|c|}{ Present } & \multicolumn{4}{|c|}{ Absent } \\
\hline & \multirow{2}{*}{$\begin{array}{c}\text { Non- } \\
\text { neoplastic }\end{array}$} & \multicolumn{3}{|c|}{ Neoplastic } & \multirow{2}{*}{$\begin{array}{c}\text { Non- } \\
\text { neoplastic }\end{array}$} & \multicolumn{3}{|c|}{ Neoplastic } \\
\hline & & $\begin{array}{c}\text { Pre } \\
\text { malignant }\end{array}$ & Malignant & Total & & $\begin{array}{c}\text { Pre } \\
\text { malignant }\end{array}$ & Malignant & Total \\
\hline No. of cases & 212 & 03 & 01 & 04 & 73 & 00 & 01 & 01 \\
\hline Total & \multicolumn{4}{|c|}{216} & \multicolumn{4}{|c|}{74} \\
\hline
\end{tabular}

Table 3: Distribution of cases according to the histopathological diagnosis and status of gallstones.

\begin{tabular}{|l|c|c|c|c|c|c|}
\hline \multirow{2}{*}{ Histopathological Diagnosis } & \multicolumn{9}{|c|}{ No. of cases } & \multirow{2}{*}{ Total (\%) } \\
\cline { 2 - 6 } & \multicolumn{3}{|c|}{ Gallstones Present } & Gallstone Absent & \multirow{2}{*}{} \\
\cline { 2 - 6 } & $\mathbf{Y}$ & $\mathbf{P}$ & $\mathbf{M}$ & Total & & \\
\hline Chronic non specific cholecystitis & 97 & 73 & 11 & 181 & 60 & $241(83.10)$ \\
\hline Acute cholecystitis & 00 & 01 & 00 & 01 & 04 & $05(1.72)$ \\
\hline Acute on chronic cholecystitis & 03 & 00 & 00 & 03 & 01 & $04(1.38)$ \\
\hline Follicular cholecystitis & 04 & 02 & 00 & 06 & 01 & $07(2.41)$ \\
\hline Eosinophilic cholecystitis & 00 & 00 & 00 & 00 & 02 & $02(0.69)$ \\
\hline Lymphoeosinophilic cholecystitis & 02 & 04 & 00 & 06 & 01 & $07(2.41)$ \\
\hline Cholesterolosis & 03 & 00 & 01 & 04 & 01 & $05(1.72)$ \\
\hline Xanthogranulomatous cholecystitis & 05 & 01 & 01 & 07 & 00 & $07(2.41)$ \\
\hline Eumycetoma & 00 & 01 & 00 & 01 & 00 & $01(0.34)$ \\
\hline Adenomyomatosis & 02 & 01 & 00 & 03 & 03 & $06(2.07)$ \\
\hline BilN & 02 & 01 & 00 & 03 & 00 & $03(1.03)$ \\
\hline Adenocarcinoma & 00 & 01 & 00 & 01 & 01 & $02(0.69)$ \\
\hline
\end{tabular}

Table abbreviations- Y: Yellow gallstone, P: Pigmented gallstone, M: Mixed gallstone, BilN: Biliary intraepithelial neoplasia 


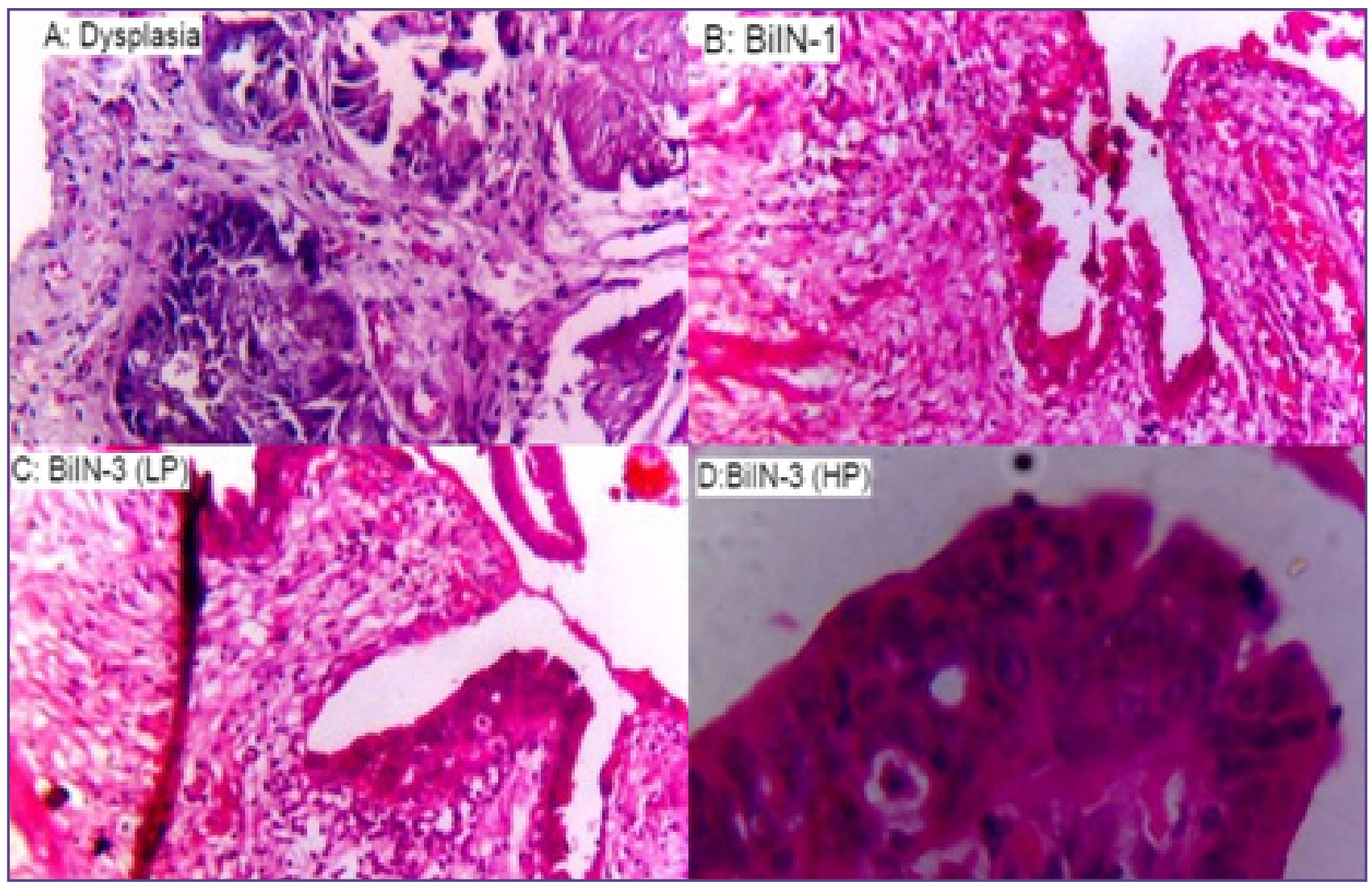

Fig.1: A)Showing dysplasia in lining epithelium. B) Case of BiIN-1: showing mild nuclear atypia (H\&E,40X). C) BiIN3:showing loss of cellular polarity with distinct nuclear atypia limited to surface epithelium (H\&E,40X) and D) BiIN-3: loss of cellular polarity and Atypical nuclei (H\&E,100X)

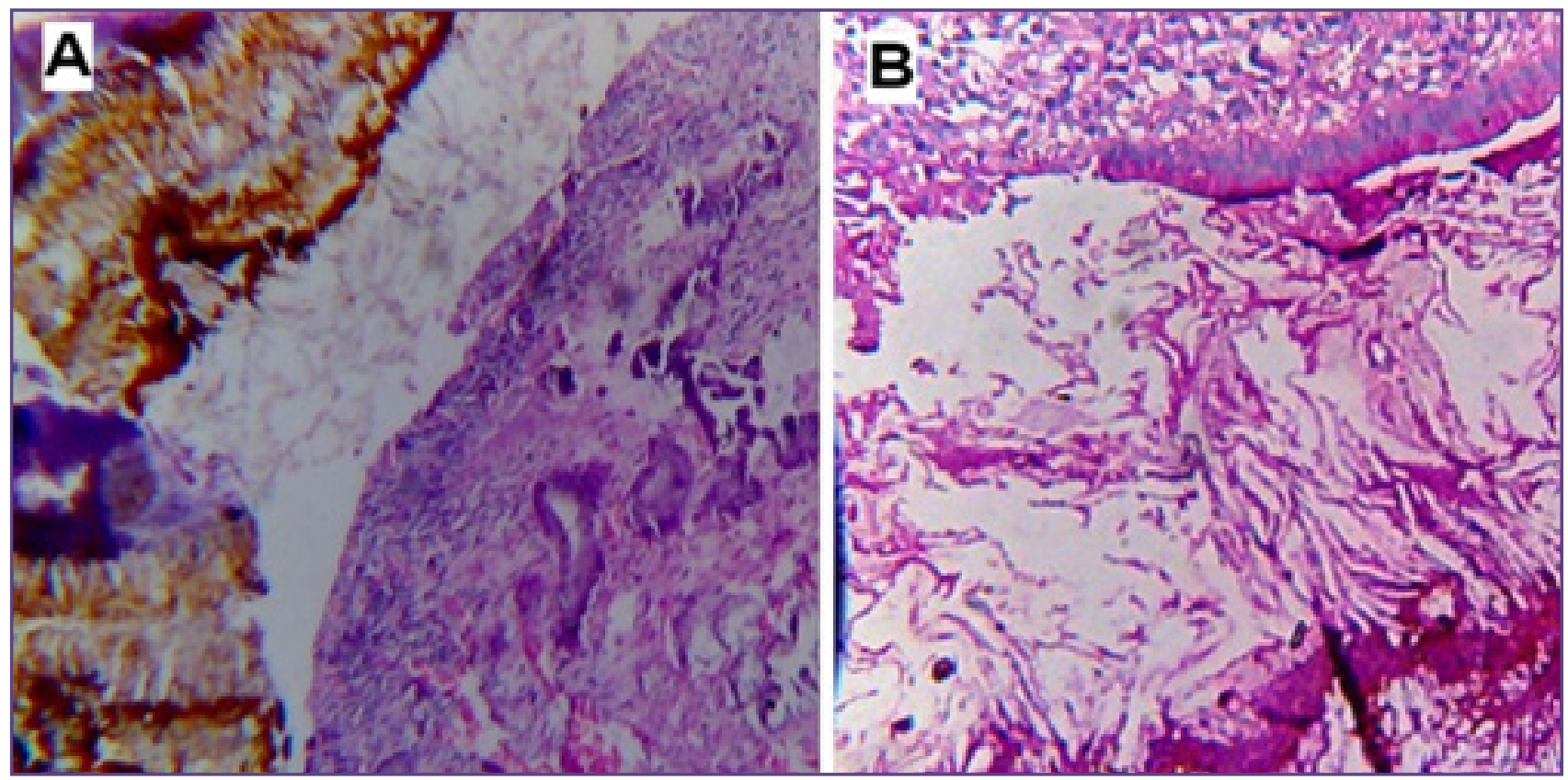

Fig. 2: Eumycetoma with chronic cholecystitis. A: Brown colored Fungal hyphae are seen in gallbladder (H\&E,40X). B: PAS positive Fungal hyphae (PAS stain,40X) 


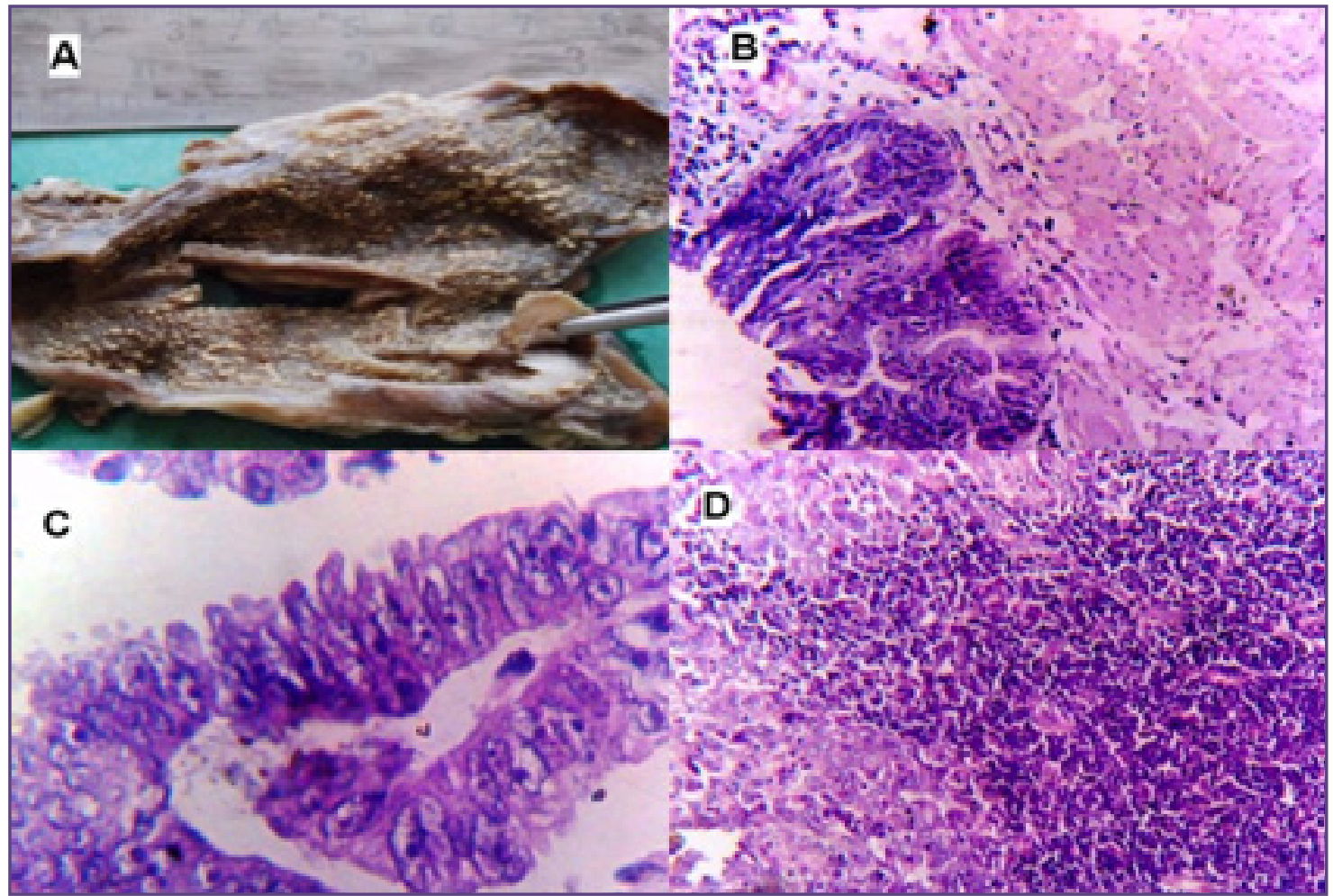

Fig. 3: Case of incidental GBC- A: Gross- small nodule seenat fundus of gall bladder. B:Adenocarcinoma (H\&E,40X). C: Adenocarcinoma (H\&E,100X). D: Metastasis of adenocarcinoma in regional Lymph Node present near cystic duct insertion (H\&E, 40X).

\section{Discussion}

While symptoms and signs of GBC clinically mimic those of gallstone disease, certain gross and microscopic findings in benign and inflammatory gallbladder disease can mimic GBC. Long standing inflammatory conditions of gallbladder causes thickening of wall with adherence to surrounding structures, this raises suspicion of GBC.

In present study, wall thickness was normal in 197 (67.93\%) cases and it was $>0.3 \mathrm{~cm}$ in 93 (32.06\%) cases. Similar findings were reported by Khanna $\mathrm{R}$ et al.$^{\left[{ }^{[13}\right]}$ while Mathur SK et al. ${ }^{[14]}$ found normal thickness in $46.4 \%$ cases and increased thickness in $53.6 \%$ cases.

Clinical Mimic of GBC: Xanthogranulomatous cholecystitis is known to mimic GBC clinically and on radiological imaging ${ }^{[15,16]}$. In present study out of five cases with clinical suspicion of GBC, xanthogranulomatous cholecystitis was reported in three cases. All seven cases of xanthogranulomatous cholecystitis showed increased wall thickness and presence of gallstones.

In present study one rare case of eumycetoma of gallbladder clinically mimicked GBC. Mycetoma is a chronic granulomatous infection mainly affecting skin and subcutaneous tissue. It is caused by fungi (eumycetoma) or by Gram positive actinomycetes bacteria (actinomycetoma). In eumycetoma the lesion grows slowly and remains encapsulated for a long period, whereas in actinomycetoma the lesion is more inflammatory and destructive. Mycetoma may present as cystic lesion ${ }^{[17]}$. Review of literature showed cases of actinomycetoma of gallbladder but so far no case of eumycetoma of gallbladder has been reported in English literature ${ }^{[18-21]}$. So to our best knowledge and research this is the first case of eumycetoma of gallbladder. Eumycetoma was differentiated from actinomycetoma on $\mathrm{H} \& \mathrm{E}$ staining by noting the color of colonies which appear homogenously eosinophilic in actinomycetoma and brown to black in eumycetoma. Confirmation was done by PAS and Gram stain. In eumycetoma fungal hyphae are PAS positive and Gram negative while in actinomycetoma causative bacteria are Gram positive.

\section{Histopathological Mimic of GBC}

In present study dysplasia was noted in three cases (1.03\%). Dysplasia is mostly an incidental finding on microscopic examination. It is seen in $40-60 \%$ cases of GBC. Dysplasia extending to Rokitansky-Aschoff sinuses (RAS) can mimic adenocarcinoma ${ }^{[22]}$. Giang et al. ${ }^{[23]}$ reported two cases of surface dysplasia which on further evaluation demonstrated numerous areas in which dysplasia was 
seen extending into RAS, mimicking transmural invasion of carcinoma. Stancu M et al. ${ }^{[24]}$ categorized dysplasia as simple, moderate and severe. They reported five cases $(50 \%)$ of simple, three cases $(30 \%)$ of moderate and two cases $(20 \%)$ of severe dysplasia. In present study, dysplasia in all three was limited to surface epithelium and one case was of BiIN-1(25\%) and two cases of BiIN-3 (75\%).

In present study, adenomyomatosis was reported in six cases $(2.07 \%)$ while Mathur SK et al. ${ }^{[14]}$ reported higher percentage (8\%). Giang et al. ${ }^{[23]}$ reported adenomyosis can be confused with adenocarcinoma. It can be differentiated from adenocarcinoma by noting cytology of glands which are usually benign in cases of adenomyomatosis. In present study, microscopic examination in all six cases showed bland cytology of glandular epithelial cells.

Intestinal metaplasia with extension to RAS can be confused with invasive adenocarcinoma. In present study, out of 14 cases (4.82\%) of intestinal metaplasia, extension to RAS was noted in five cases. Adenocarcinoma was ruled out by applying criteria given by Giang et al. ${ }^{[23]}$.

GBC : Khoo JJ et al. ${ }^{[25]}$ reported that out of 9 cases of GBC, six had abnormal macroscopic lesions in form of papillary lesions or polypoid masses and remaining three cases had thickening of wall consistent with chronic cholecystitis. Arvind K et al.[26] reported gross abnormalities in the form of ulcerated mucosa, small polypoidal elevation, nodular formation and thickened gallbladder wall in all cases of GBC. In present study gross abnormalities in mucosa in form of small nodule and black fragile tissue was reported in both cases of GBC.

In present study two cases $(0.69 \%)$ of GBC were reported on histopathology which is comparable to study by Khoo $\mathrm{JJ}$ et al.[25] and lower as compared to study by Ghimire $\mathrm{P}$ et al.[4] and Arvind K et al.[26] In study by Khoo JJ et al.[25], out of $9 \mathrm{GBC}$ cases reported on histopathology only two were clinically suspected as GBC while three cases were clinically misdiagnosed as acute or chronic cholecystitis, two as cholelithiasis and one case each as intestinal obstruction and ovarian cyst. However, intraoperatively GBC was suspected in four of these cases. Ghimire $\mathrm{P}$ et al. [4] reported that in all 10 cases of GBC that were reported on histopathology, there was no suspicion of GBC either preoperatively or intraoperatively. In present study, both cases of GBC diagnosed on histopathology were clinically misdiagnosed as cholecystitis. However intra-operatively, suspicion of GBC was raised in one case while remaining one case was of incidental GBC.

In present study histopathological diagnosis in both cases of GBC was adenocarcinoma (NOS and papillary) which is comparable to other studies which also reported adenocarcinoma as major histopathological diagnosis $[4,14,25,26]$.
In present study both cases of GBC $(100 \%)$ were reported in females which is comparable to study by Mathur SK et al. [14]. Mean age of patients with GBC in present study was 40 years while other studies reported GBC in older age group of 6th to 7 th decade of life $[4,14,25,26]$.

In present study association of gallstones with GBC was $50 \%$ which is comparable to study by Khoo JJ et al.[25] while Ghimire $\mathrm{P}$ et al.[4] and Arvind $\mathrm{K}$ et al.[26] reported higher percentage of gallstones association with GBC (upto $80-85 \%$ ).

\section{Incidental GBC}

In present study incidence of incidental GBC was $0.34 \%$ which is comparable to study by Khoo JJ et al.[25], lower as compared to studies by Ghimire $\mathrm{P}$ et al.[4], Mathur SK et al.[14], and Arvind $\mathrm{K}$ et al.[26] and higher than study by Khanna $\mathrm{R}$ et al.[13] who found only one case of in situ carcinoma and no case of invasive GBC.

In present study, case of incidental GBC had pathological staging of III B (T1bN1). Ghimire P et al.[4] reported that all 10 cases of incidental GBC showed no involvement of regional lymph nodes with eight cases having pathological staging as T1 and two cases as T2. Khoo JJ et al.[25] reported stage 1A (T1N0M0) in one case on incidental GBC and stage II (T2N1M0) in two cases of incidental GBC. While Vahini $\mathrm{G}$ et al.[27] reported one case of incidental GBC with metastasis to liver and omentum.

\section{Summary}

Thus in present study all clinically suspected cases of GBC were reported as inflammatory lesions of gallbladder on histopathology. Xanthogranulomatous cholecystitis was most common to clinically mimic as GBC. Rare case of eumycetoma of gallbladder can also clinically mimic as GBC due to its presentation of mass and sinus or fistula formation. Two cases of GBC diagnosed on histopathology presented clinically as cholecystitis. Incidence of incidental GBC in present study was $0.34 \%$.

\section{Conclusion}

The present study revealed that gallstones disease can mimic gallbladder carcinoma clinically while incidental gallbladder carcinoma can occur in grossly normal looking gallbladder. Hence all the cholecystectomy specimens should be sent for histopathology, so that incidental gall bladder carcinoma is not overlooked.

\section{References}

1. Unisa S, Jagannath P, Dhir V, Khandelwal C, Sarangi L, Roy TK. Population-based study to estimate prevalence and determine risk factors of gallbladder diseases in the rural Gangetic basin of North India. HPB (Oxford) 2011;13:117-25. 
2. Randi G, Franceschi S, La Vecchia C. Gallbladder cancer worldwide: geographical distribution and risk factors. Int $\mathrm{J}$ Cancer. 2006;118:1591-1602

3. Tantia O, Jain M, Khanna S, Sen B. Incidental carcinoma gallbladder during laparoscopic cholecystectomy for symptomatic gallstone disease. Surg Endosc 2009;23:2041-6.

4. Ghimire P, Yogi N, Shrestha BB. Incidence of incidental carcinoma gallbladder in cases of routine cholecystectomy. Kathmandu Univ Med J. 2011;34:3-6.

5. Moin M. Mode of presentation of carcinoma of gallbladder. Ann King Edward Med Coll. 2000; 10(10): 234-235

6. Roa I,Araya JC, Villaseca M, Roa J, de Aretxabala X, Ibacache G. Gallbladder cancer in a high risk area: morphological features and spread patterns. Hepatogastroenterology. 1999; 46: $1540-1546$

7. Samad A. Gallbladder carcinoma in patients undergoing cholecystectomy for cholelithiasis. J Pak Med Assoc 2005;55:497-9.

8. Royal College of Pathologists. Histopathology and cytopathology of limited or no clinical value. Report of working group of The Royal College of Pathologists, 2nd edition London:Royal College of Pathologists, 2005.

9. Darmas B, Mahmud S, Abbas A, Baker AL. Is there any justification for the routine histological examination of straightforward cholecystectomy specimens? Ann R Coll Surg Engl 2007; 89: 238-241.

10. Mittal R, Jesudason MR, Nayak S. Selective histopathology in cholecystectomy for gallstone disease. Indian $\mathrm{J}$ Gastroenterol. 2010;29:26-30

11. Romero-González RJ, Garza-Flores A, MartínezPérezMaldonado Let al. Gallbladder selection for histological analysis based on a simple method: a prospective comparative study. Ann R Coll Surg Engl 2012; 94: 159-164

12. Zen Y, Adsay NV, Bardadin K, Colombari R et al. Biliary intraepithelial neoplasia: an international interobserver agreement study and proposal for diagnostic criteria. Modern Pathology (2007) 20, 701-709.

13. Khanna R, Chansuria R, Kumar M, Shukla HS. Histological changes in gallbladder due to stone disease. Indian J Surg. 2006;68:201-4

14. Mathur SK, Duhan A, Singh S et al. Correlation of gallstone characteristics with mucosal changes in gallbladder. Tropical Gastroenterology 2012;33(1):39-44
15. Chun KA, Ha HK, Yu ES, Shinn KS, Kim KW, Lee DH, et al. Xanthogranulomatous cholecystitis:CT features with emphasis on differentiation from gall-bladder carcinoma. Radiology 1997;203:93-7.

16. Yildirim $\mathrm{M}$, Oztekin $\mathrm{O}$, Akdamar $\mathrm{F}$ et al. Xanthogranulomatous cholecystitis remains a challenge in medical practice: experience in 24 cases. Radiol Oncol 2009; 43(2):76-83.

17. Fahal AH, El Hassan AM, Abdelalla AO, Sheik HE. Cystic mycetoma: an unusual clinical presentation of Madurella mycetomatis. Trans R Soc Trop Med Hyg 1998; 92:66-67

18. Lee JH, Hwang ET, Kim KH, Jo HJ, Kim TH, Choi SC, Choi CS. A case of actinomycosis of gallbladder presenting as acute cholecystitis. Korean J Gastroenterol. 2009 Apr;53(4):261-4.

19. Marrie T, Stiver HG, Molgat A, Stark RG, Norris D. Actinomycosis of the gallbladder. Can J Surg. 1977 Mar;20(2):147-9.

20. Freland C, Massoubre B, Horeau JM, Caillon J, Drugeon HB. Actinomycosis of the gallbladder due to Actinomyces naeslundii. J Infect. 1987 Nov;15(3):251-7.

21. Hefny AF, Torab FC, Joshi S, Sebastian M, Abu-Zidan FM. Actinomycosis of the Gallbladder: Case Report and Review of the literature. Asian J Surg. 2005 Jul;28(3):230-2.

22. Katabi N. Neoplasia of Gallbladder and Biliary Epithelium. Arch Pathol Lab Med. 2010; 134:1621-1627

23. Giang et al. Carcinoma involving the gallbladder: a retrospective review of 23 cases - pitfalls in diagnosis of gallbladder carcinoma. Diagnostic Pathology 2012;7:10.

24. Stancu M, Căruntu ID, Giuşcă S and Dobrescu G Hyperplasia, metaplasia, dysplasia and neoplasia lesions in chronic cholecystitis- a morphologic study. Romanian Journal of Morphology and Embryology 2007;48(4):335-342

25. Khoo JJ, Nurul AM. A clinicopathological study of nine cases of gallbladder carcinoma in 1122 cholecystectomies in Johor, Malaysia. Malaysian J Pathol 2008; 30(1):21-6.

26. Kumar A, Chaudhari S, Bhat, Bhat P, Batra N. Frequency of gallbladder carcinoma in cholecystectomy specimens in government hospital of garhwal region of Uttarakhand. International Journal of Contemporary Medical Research 2016;3 (12):3533-3535

27. Vahini G, Premalatha P, Mathi A et al. A Clinicopathological Study of Gallbladder Lesions. IOSR Journal of Dental and Medical Sciences 2015;14(2):15-20.

*Corresponding author:

Dr. Sheetal G. Gole, Associate Professor,Department of Pathology, World College of Medical Science \& Research \& Hospital, Gurawar, Jhajjar, Haryana, India. 124001

Phone: +91 8222898476

Email: drsheetalgole@rediffmail.com

Date of Submission : 18.07.2017

Date of Acceptance : 29.10.2017

Financial or other Competing Interests: None.

Date of Publication : 28.01.2018 